Bond University

Research Repository

\title{
Topical analgesia for acute otitis media
}

Foxlee, R; Johansson, A; Wejfalk, J; Dooley, L; Del Mar, C

Published in:

Cochrane Database of Systematic Reviews

DOI:

10.1002/14651858.CD005657.pub2

Licence:

Other

Link to output in Bond University research repository.

Recommended citation(APA):

Foxlee, R., Johansson, A., Wejfalk, J., Dooley, L., \& Del Mar, C. (2006). Topical analgesia for acute otitis media. Cochrane Database of Systematic Reviews, (3), 1-42. [CD005657].

https://doi.org/10.1002/14651858.CD005657.pub2

\section{General rights}

Copyright and moral rights for the publications made accessible in the public portal are retained by the authors and/or other copyright owners and it is a condition of accessing publications that users recognise and abide by the legal requirements associated with these rights.

For more information, or if you believe that this document breaches copyright, please contact the Bond University research repository coordinator. 


\section{Bond University}

\section{ePublications@bond}

7-19-2006

\section{Topical analgesia for acute otitis media}

Ruth Foxlee

University of York

Ann-Charlotte Johansson

ABIGO Medical AB, Askim, Sweden

Jessika Wejfalk

Octean AB, Göteborg, Sweden

Liz Dooley

Bond University, Liz_Dooley@bond.edu.au

Chris Del Mar

Bond University, chris_del_mar@bond.edu.au

Follow this and additional works at: http://epublications.bond.edu.au/hsm_pubs

Part of the Otorhinolaryngologic Diseases Commons

\section{Recommended Citation}

Ruth Foxlee, Ann-Charlotte Johansson, Jessika Wejfalk, Liz Dooley, and Chris Del Mar. (2006)

"Topical analgesia for acute otitis media" ,, .

http://epublications.bond.edu.au/hsm_pubs/51 


\section{Topical analgesia for acute otitis media (Review)}

Foxlee R, Johansson A, Wejfalk J, Dawkins J, Dooley L, Del Mar C

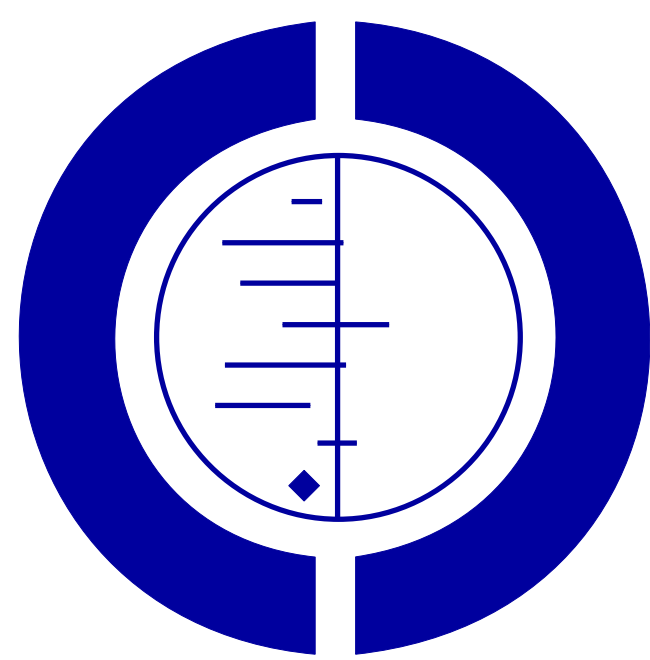

THE COCHRANE

COLLABORATION $^{\circledR}$

This is a reprint of a Cochrane review, prepared and maintained by The Cochrane Collaboration and published in The Cochrane Library 2007, Issue 2

http://www.thecochranelibrary.com

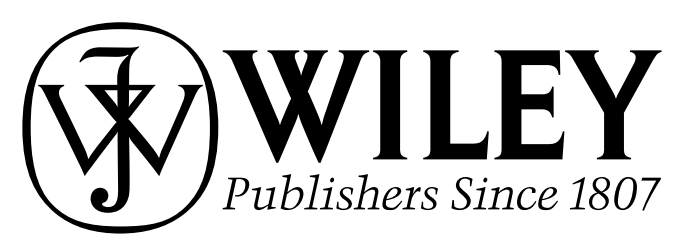

Topical analgesia for acute otitis media (Review)

Copyright $\odot 2007$ The Cochrane Collaboration. Published by John Wiley \& Sons, Ltd 


\section{TABLE OF CONTENTS}

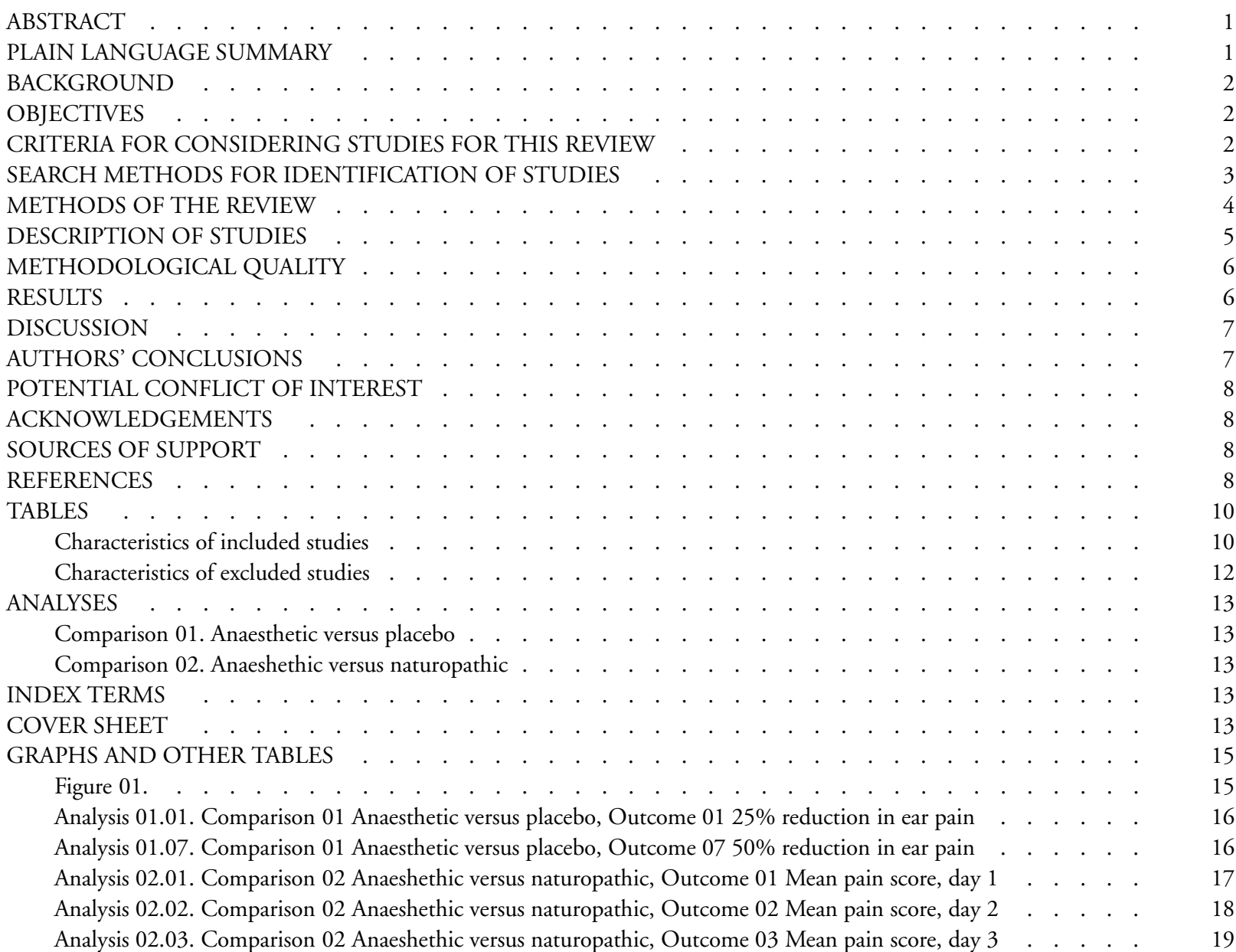




\title{
Topical analgesia for acute otitis media (Review)
}

\author{
Foxlee R, Johansson A, Wejfalk J, Dawkins J, Dooley L, Del Mar C
}

This record should be cited as:

Foxlee R, Johansson A, Wejfalk J, Dawkins J, Dooley L, Del Mar C. Topical analgesia for acute otitis media. Cochrane Database of Systematic Reviews 2006, Issue 3. Art. No.: CD005657. DOI: 10.1002/14651858.CD005657.pub2.

This version first published online: 19 July 2006 in Issue 3, 2006.

Date of most recent substantive amendment: 19 May 2006

\section{A B S T R A C T}

\section{Background}

Acute otitis media (AOM) is a spontaneously remitting disease for which pain is the most distressing symptom. Antibiotics are now known to have less benefit than previously assumed.

\section{Objectives}

To assess the effectiveness of topical analgesia for AOM.

\section{Search strategy}

We searched the Cochrane Central Register of Controlled Trials (CENTRAL) (The Cochrane Library Issue 2, 2006), MEDLINE (1966 to May Week 3 2006), EMBASE (1990 to December 2005) and LILACS (1982 to September 2005) without language restriction, and the reference lists of articles. We also contacted manufacturers and authors.

\section{Selection criteria}

Double-blind randomised or quasi-randomised controlled trials comparing an otic preparation with an analgesic effect (excluding antibiotics) versus placebo or an otic preparation with an analgesic effect (excluding antibiotics) versus any other otic preparation with an analgesic effect, in adults or children presenting at primary care settings with AOM without perforation.

\section{Data collection and analysis}

Potential studies were screened independently and trial quality was assessed by three authors, and differences were resolved by discussion. Data was then independently extracted from the trials selected by two authors. We contacted the authors of three trials to acquire additional information not available in published articles.

\section{Main results}

Our searches yielded 356 records; four trials met our criteria. One trial with 54 participants compared treatment with anaesthetic ear drops versus an olive oil placebo immediately at diagnosis. All patients were also given paracetamol. There was a statistically significant pain reduction of $25 \%$ in those receiving anaesthetic drops 30 minutes after instillation. Three trials (with one common co-author) compared anaesthetic ear drops with naturopathic herbal ear drops in 274 patients. One of these trials also used antibiotics in both groups. There were statistically significant differences at instillation of drops, or 15 or 30 minutes after the instillation (or both) on one to three days after diagnosis, always favouring the naturopathic group in each trial.

\section{Authors' conclusions}

The evidence from these four randomised controlled trials, only one of which addresses the most relevant question of primary effectiveness, is insufficient to know whether ear drops are effective or not.

\section{PLAIN LANGUAGESUMMARY}

Treating the pain of acute middle ear infection is difficult

Topical analgesia for acute otitis media (Review)

Copyright (c) 2007 The Cochrane Collaboration. Published by John Wiley \& Sons, Ltd 
Antibiotics and oral pain killers make little difference. Some advocate ear drops with local anaesthetic. Only four trials were found with adequate methods, and only one compared anaesthetic drops to placebo. The other three compared anaesthetic drops to naturopathic drops. There was not enough information to be sure whether the drops are effective or not effective. More good quality trials are needed.

\section{B A C K G R O N D}

Acute otitis media (AOM) is a very common disease of childhood and a leading cause of visits to the family doctor and antibiotic prescribing for children in high-income countries (Charles 2004; Froom 1997; Glasziou 2003; Pirozzo 2004). Although it is difficult to establish a global estimate, childhood incidence ranges between $17 \%$ and $32 \%$ per year (Pirozzo 2004).

AOM is characterised by inflammation and effusion of the middle ear accompanied by varying degrees of local pain, fever, irritability and possible erythema and deafness. The onset of symptoms and signs is rapid and the acute infection usually resolves within days. The illness can affect people at any age but occurs mainly in children, where incidence peaks between 6 and 15 months (Klein 1989). Although the morbidity rate is high, the mortality rate for healthy children in high-income countries is low. Suppurative complication rates are also low (Marcy 2001) and severe illness requiring antibiotic therapy only occurs in about $2.7 \%$ of children (Van Buchem 1985). This may not be true of low-income countries where the burden of AOM is heavier because access to medical care is limited and the risk of complications is higher (Berman 1995; Klein 2001). The impact of AOM is also greater among some indigenous populations living in high-income countries (WHO/CIBA 1996). Potential hearing loss is of particular concern in countries where illiteracy is high and the comprehension of normal speech is vital (Klein 2001).

Antibiotics have been a mainstay of treatment based on a pathophysiological model (Pirozzo 2004). A Cochrane review challenged this approach to treatment by demonstrating that the benefit from antibiotics are modest and may not outweigh their risks (Glasziou 2003). Approximately 17 children needed to be treated to prevent one child experiencing pain after two to seven days (Glasziou 2003). Another systematic review showed that $60 \%$ of children will improve spontaneously in 24 hours without any antibiotic treatment and $80 \%$ of cases will resolve within three days (Rosenfeld 2003). Antibiotics also threaten adverse effects to the individual, such as diarrhoea, stomach pain, rash and vomiting. Antibiotic use also inevitably promotes resistance by natural selection, thus limiting their usefulness for future generations (Nasrin 2002).

In recent years there has been a trend away from the prescription of antibiotics for all AOM sufferers. Generally, children over the age of two years can be treated with analgesia (Glasziou 2003). In an effort to minimise adverse effects and help guard against the selection of resistant strains some current guidelines advise against rou- tine antibiotic treatment for uncomplicated AOM (DoH 2000; SIGN 2003; Spicer 2003). The AAP guidelines (AAP 2004) offer the option, not recommendation, of initially observing selected children, primarily those aged two years or older with non-severe illness.

Even though AOM is not a life-threatening illness, the symptoms may be very distressing for sufferers, usually children, and their parents/carers. Pain is a common aspect of otitis media because the ear is so well-innervated with pain-sensitive structures. In AOM increased pressure in the middle ear stretches these structures, thus leading to the idea that topical analgesia can provide pain relief (Schecter 2003). The element of AOM-associated pain can sometimes be a peripheral concern for physicians but it is central to the patient's experience of the illness (Schecter 2003) and a common reason to seek treatment. Topical treatments may be prescribed or bought over-the-counter. In the context of reduced antibiotic prescribing for uncomplicated $\mathrm{AOM}$ it is worthwhile assessing the effectiveness of these topical treatments as an alternative to the routine prescription of antibiotics, particularly when symptomatic pain relief is such an important treatment outcome for patients and parents/carers.

\section{O B JECT IVES}

The aim of this review was to:

(i) assess the effectiveness of topical analgesia in adults and children suffering from acute otitis media without perforation;

(ii) assess whether different topical analgesic preparations differ in effect.

The primary outcome measures were severity and duration of pain. Secondary measures were parental satisfaction, days missed from school or work (for both children and parents/carers) and adverse events.

\section{CRITERIA FOR CONSIDERING STUDIES FOR THIS REVIEW}

\section{Types of studies}

All double-blind randomised or quasi-randomised controlled trials.

\section{Types of participants}

Adults and children presenting at primary care settings, suffering from acute otitis media without perforation. 


\section{Types of intervention}

(i) Any otic preparation with an analgesic effect (excluding antibiotics) versus placebo.

(ii) Any otic preparation with an analgesic effect (excluding antibiotics) versus any other otic preparation with an analgesic effect.

\section{Types of outcome measures}

Data extraction focused on patient-relevant outcomes. The primary outcome measures were severity and duration of pain. Secondary measures included at least one of the following: parental satisfaction, days missed from school or work and adverse events.

\section{SEARCH METHODS FOR IDENTIFICATIONOF TUDIES}

See: Cochrane Acute Respiratory Infections Group methods used in reviews.

We searched the Cochrane Central Register of Controlled Trials (CENTRAL) (The Cochrane Library Issue 2, 2006), MEDLINE (1966 to May Week 3 2006), EMBASE (1990 to December 2005) and LILACS (1982 to September 2005) without language restrictions and the reference lists of articles. We also contacted manufacturers and authors.

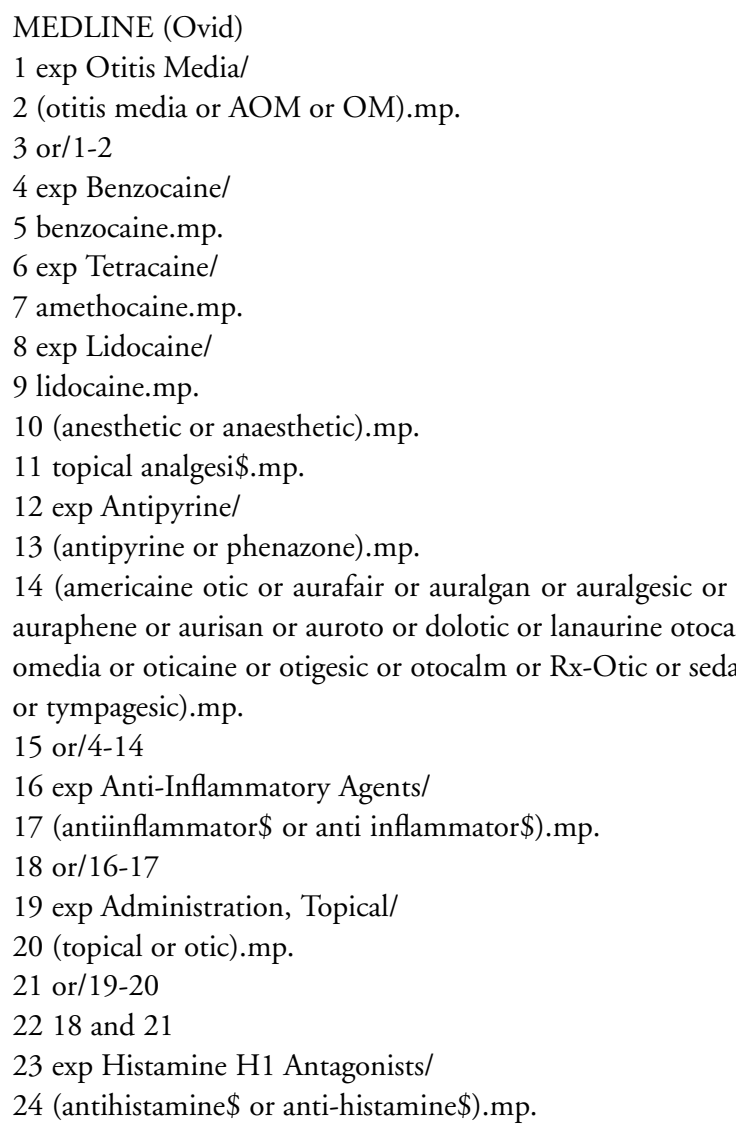

25 or/23-24

2625 and 21

27 exp Steroids/

28 steroid\$.mp.

29 or/27-28

3029 and 21

3115 or 22 or 26 or 30

323 and 31

\section{EMBASE (WebSPIRS)}

\#1 'otitis-media' / all subheadings in DEM,DER,DRM,DRR

$\# 2$ (otitis media or AOM or OM) in ti

$\# 3$ (otitis media or AOM or OM) in ab

\#4 \#1 or \#2 or \#3

\#5 'benzocaine-' / all subheadings in DEM,DER,DRM,DRR

\#6 (benzocaine in ti) or (benzocaine in ab)

\#7 'tetracaine-' / all subheadings in DEM,DER,DRM,DRR

\#8 (amethocaine in ti) or (amethocaine in ab)

\#9 'lidocaine-' / all subheadings in DEM,DER,DRM,DRR

\#10 (lidocaine in ti) or (lidocaine in ab)

\#11 (anesthetic or anaesthetic) in ti

\#12 (anesthetic or anaesthetic) in ab

\#13 (topical analgesi*) in ti

\#14 (topical analgesi*) in ab

\#15 'phenazone-' / all subheadings in DEM,DER,DRM,DR)

\#16 (antipyrine in ti) or (antipyrine in ab)

\#17 'auralgan-' / all subheadings in DEM,DER,DRM,DR)

\#18 (americaine otic or aurafair or auralgan or auralgesic or auraphene or aurisan or auroto or dolotic or lanaurine otocain or omedia or oticaine or otigesic or otocalm or Rx-Otic or sedaural or tympagesic) in ti

\#19 (americaine otic or aurafair or auralgan or auralgesic or auraphene or aurisan or auroto or dolotic or lanaurine otocain or omedia or oticaine or otigesic or otocalm or Rx-Otic or sedaural or tympagesic) in $\mathrm{ab}$

$\# 20 \# 5$ or $\# 6$ or $\# 7$ or \#8 or \#9 or \#10 or \#11 or \#12 or \#13 or $\# 14$ or \#15 or \#16 or \#17 or \#18 or \#19

\#21 'antiinflammatory-agent' / all subheadings in DEM,DER,DRM,DRR

\#22 (antiinflammator* or anti inflammator*) in ti

\#23 (antiinflammator* or anti inflammator*) in ab

\#24 \#21 or \#22 or \#23

\#25 'topical-drug-administration' / all subheadings in DEM,DER,DRM,DRR

\#26 (topical or otic) in ti

$\# 27$ (topical or otic) in ab

\#28 \#25 or \#26 or \#27

\#29 \#24 and \#28

\#30 'antihistaminic-agent' / all subheadings in

DEM,DER,DRM,DRR

\#31 (antihistamine* or anti-histamine*) in ti \#32 (antihistamine* or anti-histamine*) in ab $\# 33 \# 30$ or \#31 or \#32

Topical analgesia for acute otitis media (Review) 
\#34 \#28 and \#33

\#35 'steroid-' / all subheadings in DEM,DER,DRM,DRR

$\# 36$ (steroid in ti) or (steroid in ab)

$\# 37$ \#35 or \#36

\#38 \#28 and \#37

$\# 39 \# 20$ or \#29 or \#34 or \#38

$\# 40 \# 4$ and \#39

The references of all included trials were scanned to identify other potentially relevant studies. We contacted the manufacturers of topical analgesic preparations and authors of published trials to enquire if they were aware of any unpublished trials. Only one reply was received stating that the company had no additional unpublished data about their product.

\section{METHODSOF THEREVIEW}

\section{Quality assessment}

Combined searches of MEDLINE, EMBASE, CENTRAL and LILACS retrieved 356 citations. Titles and abstracts were reviewed independently by two authors (ACJ and JW) to exclude trials which clearly did not meet the inclusion criteria of the review. If either author felt that the trial might possibly meet the criteria, the full paper was obtained for further examination. Full copies of 29 studies were reviewed; eight trials were identified as possibly meeting the review inclusion criteria and were appraised using a modification of a published method (Chalmers 1990). The items were assessed for the following four characteristics:

1. Method of treatment assignment

a. Correct,

blinded,

randomisation method described OR randomised, double-blind stated AND group similarity documented.

b. Blinding and randomisation stated, but method not described OR suspect technique, for example, envelope.

c. Randomisation claimed but not described, and investigator not blinded.

d. Randomisation not mentioned.

2. Control of selection bias after treatment assignment

a. Intention-to-treat analysis AND full follow up.

b. Intention-to-treat analysis AND less than 15\% loss to follow up.

c. Analysis by treatment received only OR no mention of withdrawals.

d. Analysis by treatment received AND no mention of withdrawals OR more than $15 \%$ withdrawals/loss-to-follow up/post-randomisation exclusions.

3. Blinding

a. Blinding of (i) outcome assessor AND (ii) patient AND (iii) care giver.

b. Blinding of (i) outcome assessor OR (patient AND care giver). c. Blinding impossible, or unclear if blinding was carried out. d. Blinding not done.

4. Outcome assessment

a. All patients had standardised assessment.

b. No standardised assessment OR not mentioned.

The studies were assessed independently by three authors (JD, ACJ and JW) and differences of opinion were resolved by discussion. Only four trials fulfilled the criteria (Hoberman 1997; Sarrell 2001; Sarrell 2003a; Sarrell 2003b), two trials were reported in one paper (Sarrell 2003a; Sarrell 2003b). An unpublished trial (Matz 2001a) was identified through personal communications but was excluded. Reasons for exclusion for all papers, whether appraised or not, are detailed in the 'Characteristics of excluded studies' table. The references of the included trials were scanned to identify other potentially relevant studies. Letters of enquiry were sent to 17 companies that were listed in MicroMedex as manufacturers of otic pain relief preparations, in order to locate unpublished trials or data. Only one reply was received stating that the company had no additional unpublished data about their product.

\section{Data extraction}

All data from the studies were independently extracted by two authors (ACJ and JW), using data extraction forms designed and validated by the authors. Differences were resolved by discussion. Attempts to obtain missing data from trial authors were unsuccessful.

\section{Data analysis}

Pain was measured as a dichotomous outcome in one trial and as a continuous outcome in the other three trials. Forest plots for the trial with dichotomous outcomes were drawn using relative risk and $95 \%$ confidence interval (CI). Trials measuring continuous outcomes were combined and analysed using weighted mean differences (WMD) and 95\% CI. Heterogeneity between trials using continuous data was tested using both fixed and random effects models in Review Manager software and a random effects model was used in the final analyses as heterogeneity was identified. Our attempts to obtain individual patient data in order to reconstruct an intention-to-treat analysis in three of the trials were unsuccessful.

\section{Subgroup analyses}

The planned subgroup analyses of the primary outcomes were: 1) Age groups; a) children aged less than 24 months at time of randomisation; b) children aged 24 months up to 18 years at time of randomisation; c) adults aged 18 years and over at time of randomisation.

2) Different types of otic preparations with an analgesic effect - local anaesthetics, antihistamines, nonsteroidal antiinflammatories, steroids or complementary medicines.

3) Concurrent use of antibiotics.

We were unable to carry out any subgroup analyses because there were too few trials and insufficient data in the categories outlined in the protocol. 


\section{DESCRIPTION OF STUDIES}

Of the eight papers appraised, four did not meet the inclusion criteria of the review.

Two trials (Laxdal 1970; Matz 2001a) were excluded because they compared a topical otic preparation to oral antibiotics. One trial (Matz 2001a) assessed pain and parental satisfaction in children with AOM treated with either anaesthetic ear drops or amoxicillin and the trial was not double-blinded. Another trial (Laxdal 1970), which compared anaesthetic ear drops to penicillin, did not assess pain and was not double-blinded. A third trial (Weippl 1985) compared the analgesic effect of suprofen syrup to anaesthetic ear drops. This trial was neither randomised nor double-blinded and as the syrup was administered orally it was excluded. The fourth trial (Abramson 1969) examined topical anaesthesia for the tympanic membrane prior to surgery.

Four trials fulfilled the review inclusion criteria; of these, two were found in the same paper (Sarrell 2003a; Sarrell 2003b). One of the trials (Hoberman 1997) evaluated the efficacy of anaesthetic ear drops (antipyrine, benzocaine and glycerine) for treating ear pain in children with acute otitis media. Fifty-four children aged 5 to 19 years, with ear pain and a clinical diagnosis of AOM, who presented to the primary care settings or the emergency department of the Children's Hospital of Pittsburgh in Pennsylvania, were enrolled in the study. Children were excluded if they had received any analgesic medication or ear drops within the preceding five hours; were allergic to acetaminophen, antipyrine, or benzocaine; had otorrhoea, an eardrum perforation, or ventilation tubes; had ear disease other than AOM; or were judged unable to use a visual analog pain scale reliably.

Eligible children in this trial (Hoberman 1997) were randomly assigned to either five drops of the anaesthetic preparation or olive oil placebo. All children were also treated with $15 \mathrm{mg} / \mathrm{kg}$ of acetaminophen as a single dose. Ear pain was assessed upon entry to the study, then 10, 20 and 30 minutes after instillation and an average ear pain score was determined. Two visual analog scales were used; a $10 \mathrm{~cm}$ horizontal line and a $10 \mathrm{~cm}$ colour scale ranging from white (indicating no pain) through gradations of red to dark red (indicating severe pain). A $1 \mathrm{~cm}$ span in each scale was equivalent to an ear pain point. A pain score of at least three out of ten at the onset of treatment was required for study participation. Four measures were used: 1) proportion of subjects achieving $50 \%$ pain reduction; 2) proportion of subjects achieving $25 \%$ pain reduction; 3) proportion of participants showing a one or more point reduction; 4) mean score over time. No drop outs were reported but data was missing for a child at one time point.

Three trials investigated the efficacy of naturopathic herbal extracts in the management of ear pain associated with AOM. One of these (Sarrell 2001) included 110 children aged between 6 to 18 years with ear pain and for whom a clinical diagnosis of otitis media was made, enhanced by tympanometry. Children were excluded if they had used any ear drops or analgesics within the preceding four hours; had a known allergy to either of the preparations being tested; had otorrhoea, eardrum perforation, ventilation tube(s), known immune deficiency, a past history of complicated AOM, a history of treated or untreated ear disease in the two weeks prior to enrolment in the study or were unable to reliably use a visual analog pain scale.

Participants in this trial (Sarrell 2001) were randomised to receive either anaesthetic ear drops (amethocaine, phenazone and glycerine) or naturopathic herbal extract ear drops (Allium sativum, Verbascum thapsus, Calendula flores and Hypericum perforatum in olive oil). Five drops of either solution were instilled into the ear three times daily for three days. All children were treated with acetaminophen $(15 \mathrm{mg} / \mathrm{kg}$ given as a single dose). Ear pain reduction was assessed using two visual analog scales, graded 1 to 10 , with 1 signifying no pain and 10 signifying excruciating pain. Measurements of both scales were recorded separately at each time point, and then averaged to determine an overall ear pain score for each treatment group. Pain was measured upon diagnosis of $\mathrm{AOM}$ and then daily for three days; before instillation and then 15 and 30 minutes after the first instillation each day. A pain score of at least three at the onset of treatment was required for study participation. The participants were educated in the use of the pain scale and telephone interviews were conducted with parents 24 and 48 hours after the treatment period. Seven children were not included in the final analysis (five due to non-compliance and two because they were overcome by the smell of the ear drops).

In the second trial by Sarrell (Sarrell 2003a), 90 children aged 5 to 18 years with ear pain were enrolled. The diagnosis was primarily clinical, enhanced by tympanometry. In addition to the exclusion criteria in the first trial (Sarrell 2001), children with otologic or craniofacial malformations were also excluded. The children were assigned by computer-numbered randomisation to receive either anaesthetic ear drops (amethocaine, phenazone and glycerine) or naturopathic herbal extract ear drops (Allium sativum, Verbascum thapsus, Calendula flores, Hypericum perfoliatum, Lavandulla officinalis, and vitamin $\mathrm{E}$ in olive oil). The dosing schedule was five drops three times daily for three days. Ear pain was assessed by using a linear numbered scale, from 1 (no pain) to 10 (worst possible pain), a scale of five facial expressions, and a colour scale. Outcome measurement was conducted as per the 2001 trial. Four children were excluded from the final analysis because of non-compliance (they forgot to take the medicine, or could not be reached for the follow up interview).

In the third trial by Sarrell (Sarrell 2003b), 90 children aged 5 to 18 years with ear pain were enrolled. The diagnosis and exclusion criteria were as outlined above. Computer-numbered randomisation was used to assign children to treatment. Anaesthetic ear drops (five drops three times daily for three days ) plus oral amoxicillin $(80 \mathrm{mg} / \mathrm{kg} /$ day divided into three doses) were compared with naturopathic herbal extract ear drops (five drops three times 
daily for three days) plus oral amoxicillin $(80 \mathrm{mg} / \mathrm{kg} /$ day divided into three doses). Ear pain assessment and outcome measures were conducted as per Sarrell 2003a. Five children were excluded from the final analysis because of non-compliance (they forgot to take the medicine, or could not be reached for the follow up interview).

\section{METHODOLOGICAL QUALITY}

The comparison of anaesthetic ear drops to placebo (Hoberman 1997), was double-blind but method of randomisation and allocation concealment were not mentioned. The authors calculated that 27 subjects per study arm were required to detect a clinically significant reduction after 10,20 and 30 minutes of at least $50 \%$ from the baseline score. No patients were reported to have dropped out, but data were missing for one of the children at the 20 minutes evaluation time point. This child, representing 3.7\%, was not accounted for in the final analysis of that time point. The anaesthetic and placebo groups were comparable in age, sex, race, laterality of AOM and baseline ear pain score.

Method of randomisation was only mentioned in two of the trials (Sarrell 2003a; Sarrell 2003b) which reported the use of computer-generated randomisation. Allocation concealment was not discussed in either of the trials by Sarrell (Sarrell 2001, Sarrell 2003a, Sarrell 2003b). All trials were double-blinded but no details were provided for the first trial (Sarrell 2001). In the later trials (Sarrell 2003a, Sarrell 2003b) all ear drops were placed in identical bottles, the contents of which were unknown to both the participants and the study nurse. It is unclear whether this was also true of the physician who evaluated and treated the patients and recorded all of the data. Neither of the trials reported a power calculation.

None of the naturopathic herbal extract trials (Sarrell 2001, Sarrell 2003a, Sarrell 2003b) carried out an intention-to-treat analysis. Seven children (6.4\%) were excluded after randomisation in Sarrell 2001 but no information about which groups they came from was provided. We contacted the authors on this matter but no further information was forthcoming. Four out of 90 children enrolled in Sarrell 2003a were excluded due to non-compliance (one $(2.2 \%)$ in the naturopathic group and three $(6.7 \%)$ in the anaesthetic group). Five out of 90 children enrolled in the Sarrell $2003 \mathrm{~b}$ trial were excluded due to non-compliance (three $(6.7 \%)$ in the naturopathic ear drops plus antibiotics group and two (4.4\%) in the anaesthetic ear drops plus antibiotics group). The groups were similar in terms of baseline characteristics (age, sex, laterality of AOM and initial ear pain score) in all three trials.

\section{R E S U L T S}

The primary outcome measures (severity and duration of pain) specified in our protocol matched those in the included trials. But none of our selected secondary outcomes (parental satisfaction, and days missed from school or work) were addressed in these trials. Nor were any possible adverse events reported, (including stinging, pain, dermatitis and sensitisation (Rosenfeld 2005)).

In the trial that compared anaesthetic ear drops with placebo (Hoberman 1997), the anaesthetic ear drops were favoured at each time point, irrespectively of which outcome measure was used ((1) $50 \%$ pain reduction; (2) 25\% pain reduction; (3) one or more point reduction; (4) mean score over time)). However, the only between-group difference that reached statistical significance was the proportion of subjects with a $25 \%$ reduction in pain after 30 minutes $(\mathrm{P}$ value $=0.02)$. The reduction in mean ear pain score showed good agreement according to the two pain measurement scales. Within-group differences across time were all statistically significant (P value less than 0.05$)$.

In comparing anaesthetic ear drops to naturopathic drops (Sarrell 2001; Sarrell 2003a; Sarrell 2003b), a reduction in pain was seen over time in both treatment groups across all trials. In the first trial (Sarrell 2001), the anaesthetic group showed a mean pain score of 8.53 at baseline. It had declined to 5.615 minutes after instillation, and to 4.330 minutes after instillation on day 1 . The naturopathic group showed a mean pain score of 8.46 at baseline, 4.815 minutes after instillation, and 3.130 minutes after instillation.

In the second trial (Sarrell 2003a), the anaesthetic group had a mean pain score of 7.8 at baseline, 4.315 minutes after instillation, and 2.930 minutes after instillation day 1 . The naturopathic group had a mean pain score of 8.4 at baseline, 4.715 minutes after instillation, and 3.030 minutes after instillation.

In the third trial (Sarrell 2003b), the group that was given anaesthetic drops plus oral amoxicillin showed a mean pain score of 9.1 at baseline, 6.715 minutes after instillation, and 5.630 minutes after instillation on day 1 . The group that was given naturopathic drops plus oral amoxicillin showed a mean pain score of 8.7 at baseline, 5.215 minutes after instillation, and 3.530 minutes after instillation. According to the above results, it is a clear drop in pain in all the groups the first day. The following two days also show a drop in pain, but the reduction is not as pronounced. Initially we believed we could not pool the data because the two arms of Sarrell 2003b used antibiotics. However there is strong evidence to suggest that antibiotics make no difference to the level of pain within the first 24 hours (Glasziou 2003), therefore we performed a meta-analysis using all the Sarell trials for day 1 only.

The first trial (Sarrell 2001) achieved statistical significance between the groups at 30 minutes on day 1 (P value less than 0.01 ), favouring the naturopathic ear drops. In the second trial (Sarrell 2003a) there was a significant difference in pain on day 3 (P value less than 0.001), 30 minutes after instilling the drops, also supporting naturopathic ear drops. Antibiotics were given to both groups in the third trial (Sarrell 2003b), in which the naturopathic ear drops were favoured again at each time point, and the differ- 
ences reached statistical significance at 15 and 30 minutes on day 1 (P value less than 0.01 ); before instillation on day 2 ( $\mathrm{P}$ value less than 0.001); before ( $P$ value less than 0.05$)$ and 30 minutes after instillation on day 3 (P value less than 0.01 ). See Figure 01.

We performed a meta-analysis on two of the trials (Sarrell 2001; Sarrell 2003a). Forest plots showed that there was significant heterogeneity.

\section{I S C U S S I O N}

Sufficient pain relief early in the course of AOM provides potential benefits for the child as well as the parents, particularly since the reduction in pain is such an important treatment outcome. Systemic analgesia is used in the management of pain, but it has a delayed effect. The late onset may allow for a pain response pathway to become established, which might result in a prolonged discomfort. Therefore, there is a need for a quick relief of pain. A review found that antibiotics did not alter pain within the first day and only slightly reduced it in the few days following and that antibiotic treatment had no early impact and a modest overall impact on the clinical course of acute otitis media (Glasziou 2003). Because of the minor contribution of antibiotics, the promotion of resistance and the possible adverse effects, antibiotics are not always the best treatment option for AOM.

Although no adverse events were reported, these trials were not particularly well designed to detect any such events. Firstly, it was an inclusion criterion that tympanic membranes had to be intact. We know nothing about whether the drugs could cause ototoxicity through perforated tympanic membranes. Any late adverse events were not recorded. Numbers were also very small to detect anything other than very common events.

There is a surprising shortage of information about the efficacy of analgesic ear drops for AOM. There was a rapid reduction in pain after instilling ear drops in both intervention and control groups in all four trials. It is hard to know if this was the result of the natural course of the illness; the placebo effect of being in a clinical setting; the ear drops or the soothing effect of (any) liquid on the inflamed tympanic membrane. It is also possible that the pain reduction resulted from the concomitant administration of oral acetaminophen. However, the reduction seen at 15 minutes on day one is not likely an effect of acetaminophen, for which complete absorption rate ranges from 23 to 60 minutes (Watson 1989). Its about a $50 \%$ reduction. Despite the potential bias, it does give an estimate of the upper limit of effectiveness. A different trial design is needed to disentangle this, with perhaps a no-eardrop-control group as well as a placebo control.

Reporting in the four included trials was poor for some quality elements. Allocation concealment was not mentioned in any of the papers, and a lack of concealment is a potential source of bias in all studies. Intention-to-treat was not performed in three of the trials (Sarrell 2001; Sarrell 2003a; Sarrell 2003b) but the number of drop-outs was given in each trial. One of the trials (Sarrell 2001) did not specify which arm the patients dropped out of, but even in a worst case scenario, the drop-out rate in that trial would have been less than $15 \%$. Although these losses are within conventional limits it would have been reassuring to know that they did not all occur in one arm. The drop-out rate in the other two trials did not exceed 7\% (Sarrell 2003a; Sarrell 2003b). To be able to reconstruct an intention-to-treat analysis (Sarrell 2001; Sarrell 2003a; Sarrell 2003b), individual patient data was required. Attempts to contact the authors for further information were unsuccessful.

The four trials (Hoberman 1997; Sarrell 2001; Sarrell 2003a; Sarrell 2003b) all used two visual analog scales to assess pain. Pain is a subjective outcome and related to many variables, therefore selfreporting is considered as the most trustworthy way to measure pain (Mathews 1993). Children older than five years of age were selected to participate in the trials, because younger children have a limited ability to describe their pain experience (Mathews 1993). However, some clinicians will be concerned about generalising the results to the population most at risk.

Meta-analysis on two of the naturopathic drop trials (Sarrell 2001; Sarrell 2003a) revealed significant heterogeneity. The remaining naturopathic drop trial (Sarrell 2003b) used antibiotics in both groups, excluding the possibility of combining their data with the two other trials (Sarrell 2001; Sarrell 2003a).

All four trials showed only marginal differences between groups, insufficient to reach convincing statistical significance, or even clinical significance according to the a priori differences set by the investigators of the placebo controlled trial (Hoberman 1997).

Finally, one must ask whether naturopathic preparations have known analgesic properties. We contacted a practitioner of homeopathy to ask about this (Michelle Morgan of Mediherb) who told us (personal communication, 15 February 2006) that at least some of the compounds have a reputation for analgesic properties when used topically (viz Calendula flower, Mullein flower and Lavender oil). Other explanations of the intervention effect of naturopathic preparations other than a real effect require impugning the quality or fairness of the trial.

\section{A U THORS' CONCLUSIONS}

\section{Implications for practice}

The evidence from these four randomised controlled trials, only one of which addresses the most relevant question of primary effectiveness, is insufficient to know whether ear drops are effective or not. If future trials find ear drops to be even only moderately effective, for managing the pain caused by AOM, the treatment is likely to be safer, cheaper and more accessible than antibiotics. 


\section{Implications for research}

High quality, placebo controlled trials need to be conducted in order to better establish the safety and efficacy of analgesic drops for AOM.

\section{POTENTIALCONFLICTOF I N T E R E S T}

One of the co-authors, Prof. Chris Del Mar, acted briefly as a consultant for Key Pharmaceuticals. This Australian-based company is the manufacturer of the otic solution Ear Clear for Ear Ache Relief. He evaluated the results of one trial and presented evidence to the Australian Therapeutic Goods Association.

\section{ACKNOWLEDGEMENTS}

ACJ and JW would like to thank their supervisor Prof. Gunnar Tobin for his invaluable assistance with organising the work placement at Bond University. They also wish to acknowledge the support of The Sahlgrenska Academy at Göteborg University; Far- maciforbundet and the Swedish Pharmaceutical Association. The authors also wish to thank the following people for commenting on the draft protocol: Amy Zelmer, Betsy Blazek-O'Neill, Richard Rosenfeld, Nelcy Rodriguez and Paul Glasziou. In writing this review, the authors wish to thank Katja Ullrich for translating German language articles and assistance writing the background of the protocol. Also, Kumar Kuldeep for commenting on the statistical components of the draft review. Finally, we wish to thank Michelle Morgan for assisting us with information on the active ingredients present in naturopathic herbal extract ear drops.

\section{SOURCES OF SUPPORT}

\section{External sources of support}

- No sources of support supplied

\section{Internal sources of support}

- Sahlgrenska Academy SWEDEN

- Farmaciforbundet SWEDEN

- The Swedish Pharmaceutical Association SWEDEN

\section{R E F E R E N C E S}

\section{References to studies included in this review}

Hoberman 1997 \{published data only\} Hoberman A, Paradise JL, Reynolds EA, Urkin J. Efficacy of Auralgan for treating ear pain in children with acute otitis media. Archives of Pediatrics \& Adolescent Medicine 1997;151(7):675-8.

Sarrell 2001 \{published data only\} Sarrell EM, Mandelberg A, Cohen HA. Efficacy of naturopathic extracts in the management of ear pain associated with acute otitis media. Archives of Pediatrics \& Adolescent Medicine 2001;155(7):796-9.

Sarrell 2003a \{published data only\} Sarrell EM, Cohen HA, Kahan E. Naturopathic treatment for ear pain in children. Pediatrics 2003a;111(5 Pt 1):574-9.

Sarrell 2003b \{published data only\}

Sarrell EM, Cohen HA, Kahan E. Naturopathic treatment for ear pain in children. Pediatrics 2003b;111(5 Pt 1):e574-9.

\section{References to studies excluded from this review}

Abramson 1969

Abramson M. Topical anesthesia of the tympanic membrane. Archives of Otolaryngology 1969;90(2):147-9.

\section{Brunet 1970}

Brunet J, Cozette P. [Clinical study of Otipax in infectious and barotraumatic pathology of the middle ear]. Therapeutique 1970;46(4): 399-401.

Busmann 1967

Busmann GJ. [Local therapy of diseases of the middle ear]. Therapie der Gegenwart 1967;106(10):1326-9.
Comeau 1978

Comeau M, Brummett R. Anesthesia of the human tympanic membrane by iontophoresis of a local anesthetic. The laryngoscope 1978; 88(2 Pt 1):277-85.

Fay 2003

Fay DL, Schellhase KG, Wujek D. Naturopathic ear drops minimally effective for acute otitis media. The Journal of Family Practice 2003; 52(9):673, 676 .

\section{Fort 2000}

Fort G. Analgesia in otorhinolaryngological diseases: Lysine clonixinate versus ibuprofen [Analgesia en afecciones otorrinolaringologicas Clonixinato de Lisina vs. Ibuprofeno]. Prensa Medica Argentina 2000;87(4):409-418.

\section{Francois 1993}

Francois M. [Efficacy and tolerance of a local application of phenazone and chlorhydrate lidocaine (Otipax) in infants and children with congestive otitis]. Annales de Pediatrie 1993;40(7):481-4.

Francois 1995

Francois M. [Treatment of acute otitis media]. Archives de Pédiatrie 1995;2(1):86-8.

Koeppel 1970 Koeppel FW. [Treatment of diseases of the ear canal and middle ear with Otobacid]. Munchener Medizinische Wochenschrift 1970;112 (17):806-9

\section{Lacher 1969}

Lacher G. [Clinical trial of Otipax: auricular pulverizations]. Revue de Laryngologie, D' Otologie et de Rhinologie 1969;90(11):719-22. 


\section{Laszlo 1981}

Laszlo I, Pupp L. Anaesthesia of tympanic membrane with lidocaine. Therapia Hungarica 1981;29(4):176-9.

\section{Laxdal 1970}

Laxdal OE. Treatment of acute otitis media: a controlled study of 142 children. Canadian Medical Association Journal 1970;102(3):263-8.

\section{MacPhail 1996}

MacPhail E. Acute otitis media. Canadian Pharmaceutical Journal 1996;129(1):29-31.

\section{Matz 2001a}

Matz PS, Webster RA, Vivier P, Alario A. Use of a Topical Otic Analgesic as a Treatment Strategy for Acute Otitis Media. Unpublished manuscript presented at the Pediatric Academic Society Meeting; 2001; Baltimore:Pediatric Academic Society Meeting; 2001; Baltimore; 2001.

\section{Matz 2001b}

Matz PS, Batista D, Vivier P, Alario AJ. Can a topical otic anesthetic reduce the need for antibiotics in acute otitis media?. Pediatric Research 2001;49:131A.

McConaghy 2001

McConaghy JR. The evaluation and treatment of children with acute otitis media. The Journal of Family Practice 2001;50(5):457-9, 4635.

\section{Menshikov 1968}

Menshikov NM. The use of lyase and desoxyribonuclease in acute otitis in children. Zhurnal Ushnykh, Nosovykh i Gorlovykh Boleznei 1968;28(2):77-9.

\section{Millard 1969}

Millard J. [On the local treatment of infections of the ear canal and middle ear]. Deutsches Medizinisches Journal 1969;20(6):181-4.

\section{Polyakova 1991}

Polyakova TS, Voznesensky NL, Mironov AA, Al Sakir M. Otinum in the therapy of middle ear diseases. Vestnik-Oto-Rino-Laringologii 1991;53(2):56-58.

\section{Reiss 2002}

Reiss G, Reiss M. [Otorhinolaryngology--4: Pro and contra of ear drops]. Pflege Zeitschrift 2002;55(2):86-8.

\section{Sano 1995}

Sano F, Sole D, Naspitz CK, Takara CK. Otitis media in children. Brasileira-de-Medicina 1995;52:113-122.

\section{Shikowitz 1989}

Shikowitz MJ. Otitis media. Children's-Hospital-Quarterly 1989;1(4): 289-299.

\section{Silverstein 1969}

Silverstein H, Call DL. Tetracaine base. An effective surface anesthetic for the tympanic membrane. Archives of Otolaryngology 1969; 90(2):150-1.

\section{Weippl 1985}

Weippl G, Michos N, Stocker H. Clinical experience and results of treatment with suprofen in pediatrics. 4th communication: Assessment of pain in babies and infants/Analgesic effect of suprofen syrup in otitis media. Arzneimittelforschung 1985;35(11):1732-4.

\section{Willenberg 1975}

Willenberg W. [New preparation for the treatment of inflammatory ear diseases]. Zeitschrift fur Allgemeinmedizin 1975;51(16):759-62.

\section{Woldman 1998}

Woldman S. Treating ear pain in children with acute otitis media. Archives of Pediatrics \& Adolescent Medicine 1998;152(1):102.

\section{Additional references \\ AAP 2004}

American Academy of Pediatrics Subcommittee on Management of Acute Otitis Media. Diagnosis and management of acute otitis media. Pediatrics 2004;113:1451-65.

\section{Berman 1995}

Berman S. Otitis media in developing countries. Pediatrics 1996;96: 126-31.

\section{Chalmers 1990}

Chalmers I, Adams M, Dickersin K, Hetherington J, Tarnow-Mordi W, Meinert C, et al. A cohort study of summary reports of controlled trials. The Journal of the American Medical Association 1990;263(10): 1401-5.

\section{Charles 2004}

Charles J, Pan Y, Britt H. Trends in childhood illness and treatment in Australian general practice, 1971-2001. Medical Journal of Australia 2004;180:216-9.

\section{DoH 2000}

Department of Health Standing Medical Advisory Committee Subgroup on Antimicrobial Resistance 2000 Department of Health Standing Medical Advisory Committee Subgroup on Antimicrobial Resistance. The path of least resistance-main report. London: $\mathrm{DoH}$ 2000. www.advisorybodies.doh.gov.uk/smac1.htm (Accessed $16 \mathrm{Au-}$ gust 2005).

Froom 1997

Froom J, Culpepper L, Jacobs M. Antimicrobials for acute otitis media? A review from the International Primary Care Network. The British Medical Journal 1997;315:98-102.

\section{Glasziou 2003}

Glasziou PP, Del Mar CB, Sanders SL, Hayem M. Antibiotics for acute otitis media in children. In: The Cochrane Database of Systematic Reviews, 4, 2003.

\section{Klein 1989}

Klein JO. Epidemiology of otitis media. Pediatric Infectious Disease Journal 1989;8(Suppl 1):89.

\section{Klein 2001}

Klein JO. The burden of otitis media. Vaccine 2001;19(Suppl):2-8.

\section{Marcy 2001}

Marcy M, Takata G, Shekelle P, et al. Management of Acute Otitis Media. Evidence Report/Technology Assessment No. 15. (Prepared by the Southern California Evidence-based Practice Center under Contract No. 290-97-0001). 2001 AHRQ Publication No. 01-E010. Rockville, MD: Agency for Healthcare Research and Quality; Vol. May.

\section{Mathews 1993}

Mathews JR, McGrath PJ, Pigeon H. Assessment and measurement of pain in children. Pain in Infants, Children, and Adolescents. Williams and Wilkins, 1993.

\section{Nasrin 2002}

Nasrin D, Collignon PJ, Roberts L, Wilson EJ, Pilotto LS, Douglas RM. Effect of beta lactam antibiotic use in children on pneumococcal 
resistance to penicillin: prospective cohort study. The British Medical Journal 2002;324(7328):324-8.

Pirozzo 2004

Pirozzo S, Del Mar C. Otitis media. In: Evidence-based Pediatrics and Child Health. 2nd Edition. BMJ Books, 2004.

\section{Rosenfeld 2003}

Rosenfeld RM. Natural history of untreated otitis media. Laryngoscope 2003;113:1645-57.

\section{Rosenfeld 2005}

Rosenfeld R. Personal communication 2005.

\section{Schecter 2003}

Schecter NL. Management of common pain problems in the primary care pediatric setting. Pain in infants, children and adolescents. 2nd Edition. Lippincott Williams \& Wilkins, 2003.

\section{SIGN 2003}

Scottish Intercollegiate Guidelines Network. Guideline 66: Diagnosis and management of childhood otitis media in primary care: a national clinical guideline. http://www.sign.ac.uk/guidelines/fulltext/ 66/index.html (Accessed 16 August 2005) 2003.

\section{Spicer 2003}

Spicer WJ, Christiansen K, Currie BJ, Dartnell JGA, Ferguson JK, Garland SM. Therapeutic Guidelines: Antibiotic. Version 12. North Melbourne: Therapeutic Guidelines Limited, 2003.

\section{Van Buchem 1985}

Van Buchem FL, Peeters MF, van'T Hof MA. Acute otitis media: a new treatment strategy. British Medical Journal (Clin Res Ed) 1985; 290(6474):1033-7.

\section{Watson 1989}

Watson PD, Mortensen ME. Pharmacokinetics of common analgesics, antiinflammatories and antipyretics in children. Clinical Pharmacokinetics 1989;17:116-137.

\section{WHO/CIBA 1996}

WHO/CIBA Foundation Workshop. Prevention of hearing impairment from chronic otitis media. WHO/PDH/98.4 1996.

T A B LE S

\section{Characteristics of included studies}

\begin{tabular}{ll} 
Study & Hoberman $\mathbf{1 9 9 7}$ \\
\hline Methods & $\mathrm{R}=$ randomisation claimed, but method not described. \\
& Baseline comparability documented. Investigators were unaware of treatment assignment. \\
& Intention to treat analysis. \\
\hline Participants & USA \\
& 54 children in \\
& primary care or emergency department aged 5 to 19 years with ear pain and eardrum findings indicative of \\
& AOM. \\
\hline Interventions & Treatment: anaesthetic ear drops (antipyrine, benzocaine, glycerine) \\
& Control: olive oil drops \\
\hline Topical analgesia for acute otitis media (Review) \\
Copyright @ 2007 The Cochrane Collaboration. Published by John Wiley \& Sons, Ltd
\end{tabular}




\section{Characteristics of included studies (Continued)}

Duration: 30 minutes

All children were also given acetaminophen $(15 \mathrm{mg} / \mathrm{kg}$ in a single dose)

Outcomes

Ear pain was assessed by means of 2 visual analog scales at baseline, 10, 20, 30 minutes after instillation, and an average ear pain score was determined.

Four measures were used:

1) proportion of subjects who showed $50 \%$ reduction

2) proportion of subjects who showed $25 \%$ reduction

3) proportion of subjects who showed a 1 or more point reduction

4) mean score over time

Notes

Allocation concealment $\mathrm{B}-$ Unclear

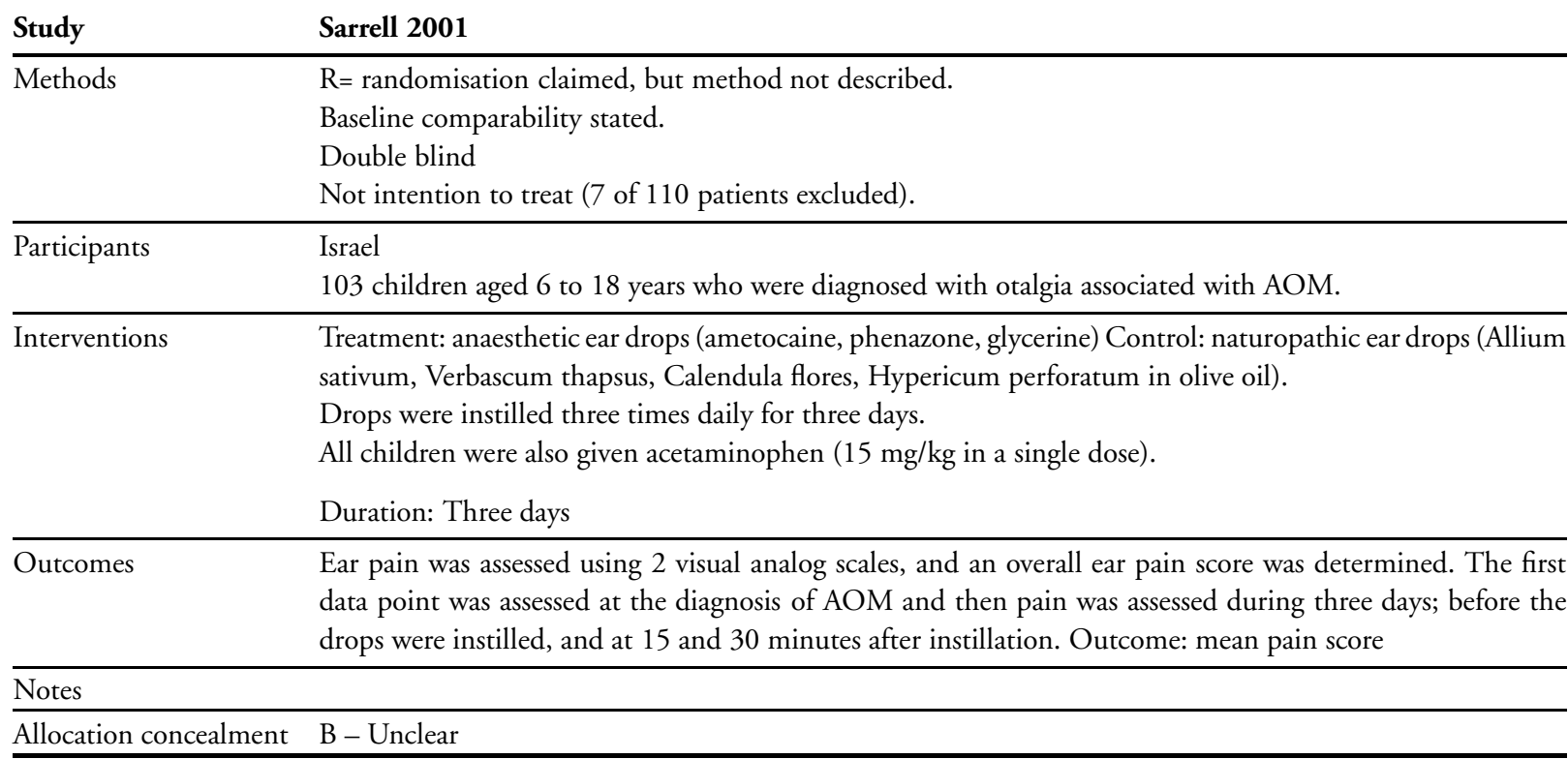

\section{Study}

Methods

\section{Sarrell 2003a}

$\mathrm{R}=$ computer-numbered randomisation. Baseline comparability documented.

Identical bottles.

Double blind.

Not intention to treat (4 of 90 patients were excluded).

Participants Israel

86 children in an ambulatory clinic aged 5 to 18 years with ear pain caused by AOM.

Interventions

Treatment: anaesthetic ear drops (ametocaine, phenazone, glycerine) Control: naturopathic ear drops (Allium sativum, Verbascum thapsus, Calendula flores, Hypericum perforatum, lavendulla officinalis and Vitamin E in olive oil).

Drops were instilled three times daily for three days.

Duration: Three days

Outcomes

Ear pain was assessed using 2 visual analog scales, and an overall ear pain score was determined. The first data point was assessed at the diagnosis of AOM and then pain was assessed during three days; before the drops were installed, and at 15 and 30 minutes after instillation. Outcome: mean pain score

\begin{tabular}{ll} 
Notes \\
\hline Allocation concealment B - Unclear \\
\hline Topical analgesia for acute otitis media (Review)
\end{tabular}

Copyright $\odot 2007$ The Cochrane Collaboration. Published by John Wiley \& Sons, Ltd 


\begin{tabular}{ll} 
Study & Sarrell 2003b \\
\hline Methods & R= computer-numbered randomisation. \\
Baseline comparability documented. & Ear drops in identical bottles. \\
& Double blind. \\
& Not intention to treat (5 of 90 patients were excluded). \\
\hline Participants & Israel \\
& 85 children in an ambulatory clinic aged 5 to 18 years with ear pain caused by AOM. \\
\hline Interventions & Treatment: anaesthetic ear drops (ametocaine, phenazone, glycerine) Control: naturopathic ear drops (Allium \\
& sativum, Verbascum thapsus, Calendula flores, Hypericum perforatum, lavendulla officinalis and Vitamin E \\
& in olive oil). \\
& Drops were instilled three times daily for three days. \\
& All children were also given oral amoxicillin (80mg/kg/day divided into three doses). \\
& Duration: Three days \\
\hline Outcomes & $\begin{array}{l}\text { Ear pain was assessed using } 2 \text { visual analog scales, and an overall ear pain score was determined. The first } \\
\text { data point was assessed at the diagnosis of AOM and then pain was assessed during three days; before the } \\
\text { drops were installed, and at } 15 \text { and } 30 \text { minutes after instillation. Outcome: mean pain score }\end{array}$ \\
\hline Notes & B - Unclear \\
\hline Allocation concealment & \\
\hline
\end{tabular}

\section{Characteristics of excluded studies}

\begin{tabular}{|c|c|}
\hline Study & Reason for exclusion \\
\hline Abramson 1969 & For surgery, not for AOM \\
\hline Brunet 1970 & No control group \\
\hline Busmann 1967 & No original data, review only \\
\hline Comeau 1978 & $\begin{array}{l}\text { Iontophoresis. } \\
\text { For myringotomy or ventilation tube placement, not AOM }\end{array}$ \\
\hline Fay 2003 & No original data, comments on a previous trial (Sarrell 2003a; Sarrell 2003b). \\
\hline Fort 2000 & Oral not topical administration of pain relief \\
\hline Francois 1993 & Treatment of congestive myringitis, not AOM \\
\hline Francois 1995 & No original data, an overview \\
\hline Koeppel 1970 & No original data, review only \\
\hline Lacher 1969 & No control group \\
\hline Laszlo 1981 & Anaesthesia of tympanic membrane, not for AOM \\
\hline Laxdal 1970 & Not double-blinded; intervention not appropriate \\
\hline MacPhail 1996 & Descriptive article \\
\hline Matz 2001a & Not double-blinded; intervention not appropriate \\
\hline Matz 2001b & No original data, referring to data in an unpublished study (Matz) \\
\hline McConaghy 2001 & No original data; review only \\
\hline Menshikov 1968 & No control group \\
\hline Millard 1969 & No control group \\
\hline Polyakova 1991 & Unclear if randomised and blinded, unable to contact authors \\
\hline
\end{tabular}


Characteristics of excluded studies (Continued)

\begin{tabular}{ll} 
Reiss 2002 & No original data; an overview \\
\hline Sano 1995 & No original data; an overview \\
\hline Shikowitz 1989 & No original data; review only \\
\hline Silverstein 1969 & No control group; for insertion of tympanic membrane tubes, not for AOM \\
\hline Weippl 1985 & Neither randomised nor double-blinded; oral treatment \\
\hline Willenberg 1975 & No control group \\
\hline Woldman 1998 & No original data; comments on a previous trial (Hoberman 1997) \\
\hline
\end{tabular}

\section{A NALYSES}

\section{Comparison 01. Anaesthetic versus placebo}

\begin{tabular}{|c|c|c|c|}
\hline Outcome title & $\begin{array}{lc}\text { No. of } & \text { No. of } \\
\text { studies } & \text { participants }\end{array}$ & Statistical method & Effect size \\
\hline $0125 \%$ reduction in ear pain & & Relative Risk (Fixed) 95\% CI & Totals not selected \\
\hline $0750 \%$ reduction in ear pain & & Relative Risk (Fixed) 95\% CI & Totals not selected \\
\hline
\end{tabular}

\section{Comparison 02. Anaeshethic versus naturopathic}

\begin{tabular}{|c|c|c|c|c|}
\hline Outcome title & $\begin{array}{l}\text { No. of } \\
\text { studies }\end{array}$ & $\begin{array}{c}\text { No. of } \\
\text { participants }\end{array}$ & Statistical method & Effect size \\
\hline 01 Mean pain score, day 1 & & & Weighted Mean Difference (Random) 95\% CI & Subtotals only \\
\hline 02 Mean pain score, day 2 & & & Weighted Mean Difference (Random) 95\% CI & Subtotals only \\
\hline 03 Mean pain score, day 3 & & & Weighted Mean Difference (Random) 95\% CI & Subtotals only \\
\hline
\end{tabular}

\section{INDEX TERMS}

\section{Medical Subject Headings (MeSH)}

Acute Disease; Analgesia [ ${ }^{*}$ methods]; Anesthetics, Local [ ${ }^{*}$ therapeutic use]; Anti-Bacterial Agents [therapeutic use]; Otitis Media [complications; *drug therapy]; Otitis Media with Effusion [complications; drug therapy]; Pain [*drug therapy; etiology]; Randomized Controlled Trials

MeSH check words

Child; Humans

\section{COVER SHEET}

Title

\section{Authors}

\section{Contribution of author(s)}

Issue protocol first published

Review first published
Topical analgesia for acute otitis media

Foxlee R, Johansson A, Wejfalk J, Dawkins J, Dooley L, Del Mar C

Designing the review: RF, ACJ, JW, CDM and LD

Coordinating the review: RF

Literature searches: RF, ACJ and JW

Quality assessment: ACJ, JW and RF

Data extraction: ACJ and JW

Data analysis: ACJ, JW, CDM and RF

Writing the review: ACJ, JW, RF, CDM, JD and LD

2006/1

$2006 / 3$

Topical analgesia for acute otitis media (Review)

Copyright (c) 2007 The Cochrane Collaboration. Published by John Wiley \& Sons, Ltd 
Date of most recent amendment

Date of most recent

SUBSTANTIVE amendment

What's New

Date new studies sought but

none found

Date new studies found but not yet included/excluded

Date new studies found and included/excluded

Date authors' conclusions section amended

Contact address

DOI

Cochrane Library number

Editorial group

Editorial group code
26 September 2006

19 May 2006

Information not supplied by author

22 May 2006

Information not supplied by author

01 August 2005

Information not supplied by author

Ruth Foxlee

Trials Search Co-ordinator

Cochrane Wounds Group

Health Sciences, University of York

Area 2 Seebohm Rowntree Building

Heslington

York

YO10 5DD

UK

E-mail: rf518@york.ac.uk

Tel: +44 1904321351

Fax: +44 1904321739

10.1002/14651858.CD005657.pub2

CD005657

Cochrane Acute Respiratory Infections Group

HM-ARI 
GRAPHS AND OTHER TABLES

Figure 0 I.

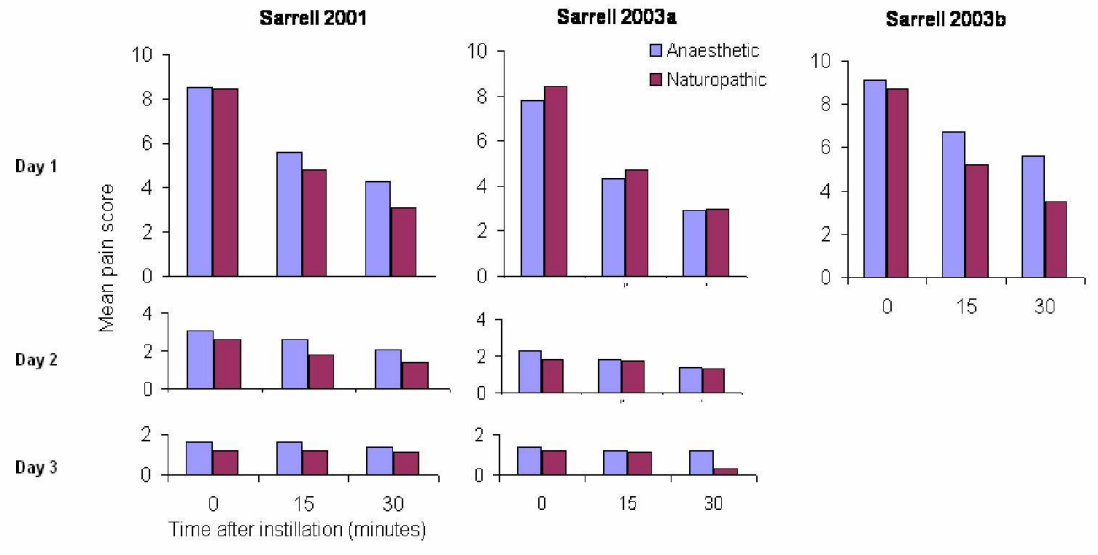

Topical analgesia for acute otitis media (Review)

Copyright $\odot 2007$ The Cochrane Collaboration. Published by John Wiley \& Sons, Ltd 
Analysis 01.01. Comparison 01 Anaesthetic versus placebo, Outcome $0125 \%$ reduction in ear pain Review: Topical analgesia for acute otitis media Comparison: 01 Anaesthetic versus placebo

Outcome: $0125 \%$ reduction in ear pain

\begin{tabular}{|c|c|c|c|c|}
\hline Study & $\begin{array}{c}\text { Anaesthetic drops } \\
n / N\end{array}$ & $\begin{array}{c}\text { Placebo } \\
\mathrm{n} / \mathrm{N}\end{array}$ & $\begin{array}{c}\text { Relative Risk (Fixed) } \\
\qquad 95 \% \mathrm{Cl}\end{array}$ & $\begin{array}{c}\text { Relative Risk (Fixed) } \\
\qquad 95 \% \mathrm{Cl}\end{array}$ \\
\hline \multicolumn{5}{|c|}{ OI 10 minutes after instillation } \\
\hline Hoberman 1997 & $13 / 27$ & $11 / 27$ & $\longrightarrow$ & $1.18[0.65,2.15]$ \\
\hline \multicolumn{5}{|c|}{0220 minutes after instillation } \\
\hline Hoberman 1997 & $21 / 27$ & $17 / 27$ & 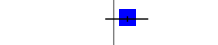 & $1.24[0.87,1.76]$ \\
\hline \multicolumn{5}{|c|}{0330 minutes after instillation } \\
\hline Hoberman 1997 & $26 / 27$ & $19 / 27$ & 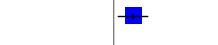 & $1.37[1.06,1.77]$ \\
\hline
\end{tabular}

Analysis 01.07. Comparison 01 Anaesthetic versus placebo, Outcome $0750 \%$ reduction in ear pain Review: Topical analgesia for acute otitis media Comparison: 01 Anaesthetic versus placebo Outcome: $0750 \%$ reduction in ear pain

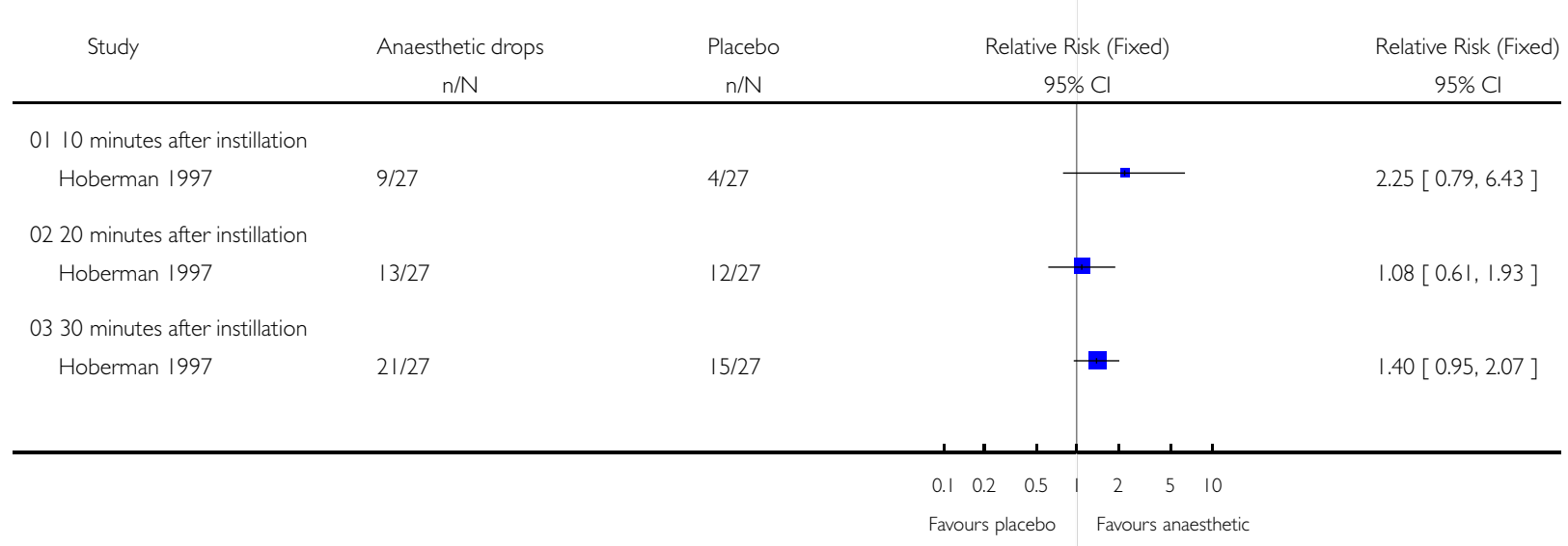




\section{Analysis 02.01. Comparison 02 Anaeshethic versus naturopathic, Outcome 01 Mean pain score, day I}

Review: Topical analgesia for acute otitis media

Comparison: 02 Anaeshethic versus naturopathic

Outcome: 0 I Mean pain score, day I

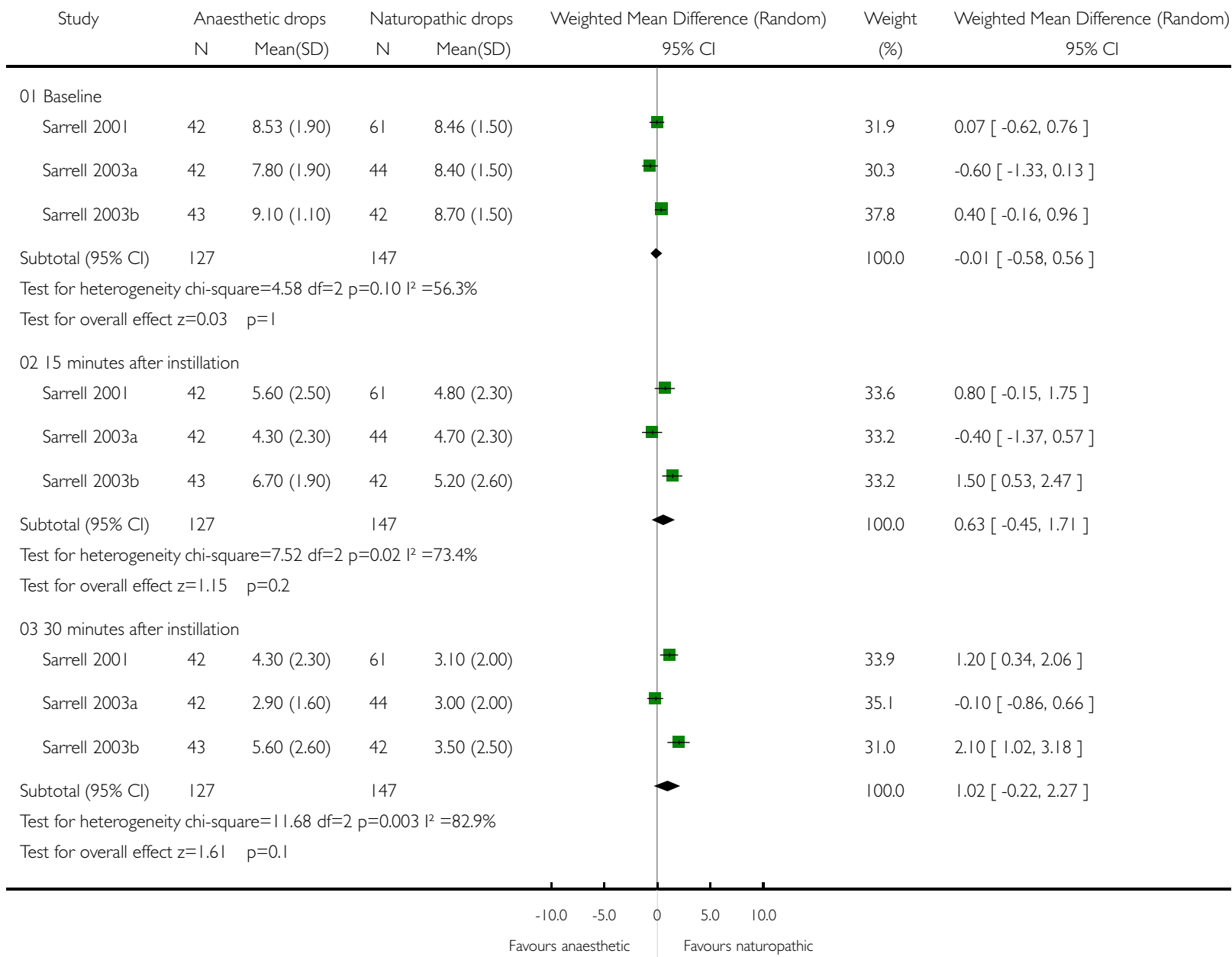




\section{Analysis 02.02. Comparison 02 Anaeshethic versus naturopathic, Outcome 02 Mean pain score, day 2}

Review: Topical analgesia for acute otitis media

Comparison: 02 Anaeshethic versus naturopathic

Outcome: 02 Mean pain score, day 2

Study Anaesthetic drops Naturopathic drops

Weighted Mean Difference (Random)

Weight

Weighted Mean Difference (Random)

N Mean(SD)

N Mean(SD)

$95 \% \mathrm{Cl}$

(\%)

$95 \% \mathrm{Cl}$

0I Before instillation

$\begin{array}{ccccc}\text { Sarrell 200I } & 42 & 3.10(1.60) & 61 & 2.60(1.70) \\ \text { Sarrell 2003a } & 42 & 2.30(1.30) & 44 & 1.80(1.70) \\ & & & 105 & \end{array}$

Subtotal $(95 \% \mathrm{Cl}) \quad 84 \quad 105$

Test for heterogeneity chi-square $=0.00 \mathrm{df}=\mid \mathrm{p}=1.00 \mathrm{|}^{2}=0.0 \%$

Test for overall effect $z=2.16 \quad p=0.03$

0215 minutes after instillation

$\begin{array}{ccccc}\text { Sarrell 200I } & 42 & 2.60(1.30) & 61 & 1.80(1.20) \\ \text { Sarrell 2003a } & 42 & 1.80(1.10) & 44 & 1.70(1.20) \\ \text { Subtotal }(95 \% \mathrm{Cl}) & 84 & & 105 & \end{array}$

Test for heterogeneity chi-square $=3.9|d f=| p=\left.0.05\right|^{2}=74.4 \%$

Test for overall effect $z=1.28 \quad p=0.2$

0330 minutes after instillation

$\begin{array}{ccccccc}\text { Sarrell 2001 } & 42 & 2.10(1.10) & 61 & 1.40(0.90) & 48.8 & 0.70[0.30,1.10] \\ \text { Sarrell 2003a } & 42 & 1.40(0.80) & 44 & 1.30(0.90) & 51.2 & 0.10[-0.26,0.46] \\ \text { Subtotal }(95 \% \mathrm{Cl}) & 84 & & 105 & & 100.0 \quad 0.39[-0.19,0.98]\end{array}$

Test for heterogeneity chi-square $=4.75 d f=|p=0.03|^{2}=79.0 \%$

Test for overall effect $z=1.31 \quad p=0.2$

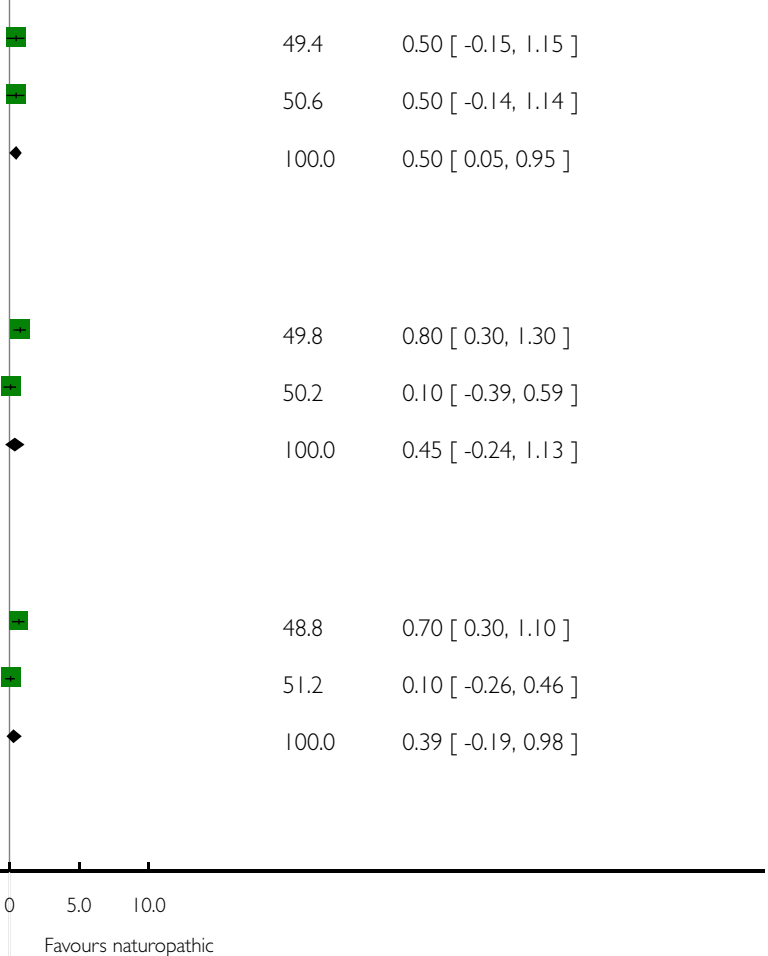


Analysis 02.03. Comparison 02 Anaeshethic versus naturopathic, Outcome 03 Mean pain score, day 3 Review: Topical analgesia for acute otitis media

Comparison: 02 Anaeshethic versus naturopathic

Outcome: 03 Mean pain score, day 3

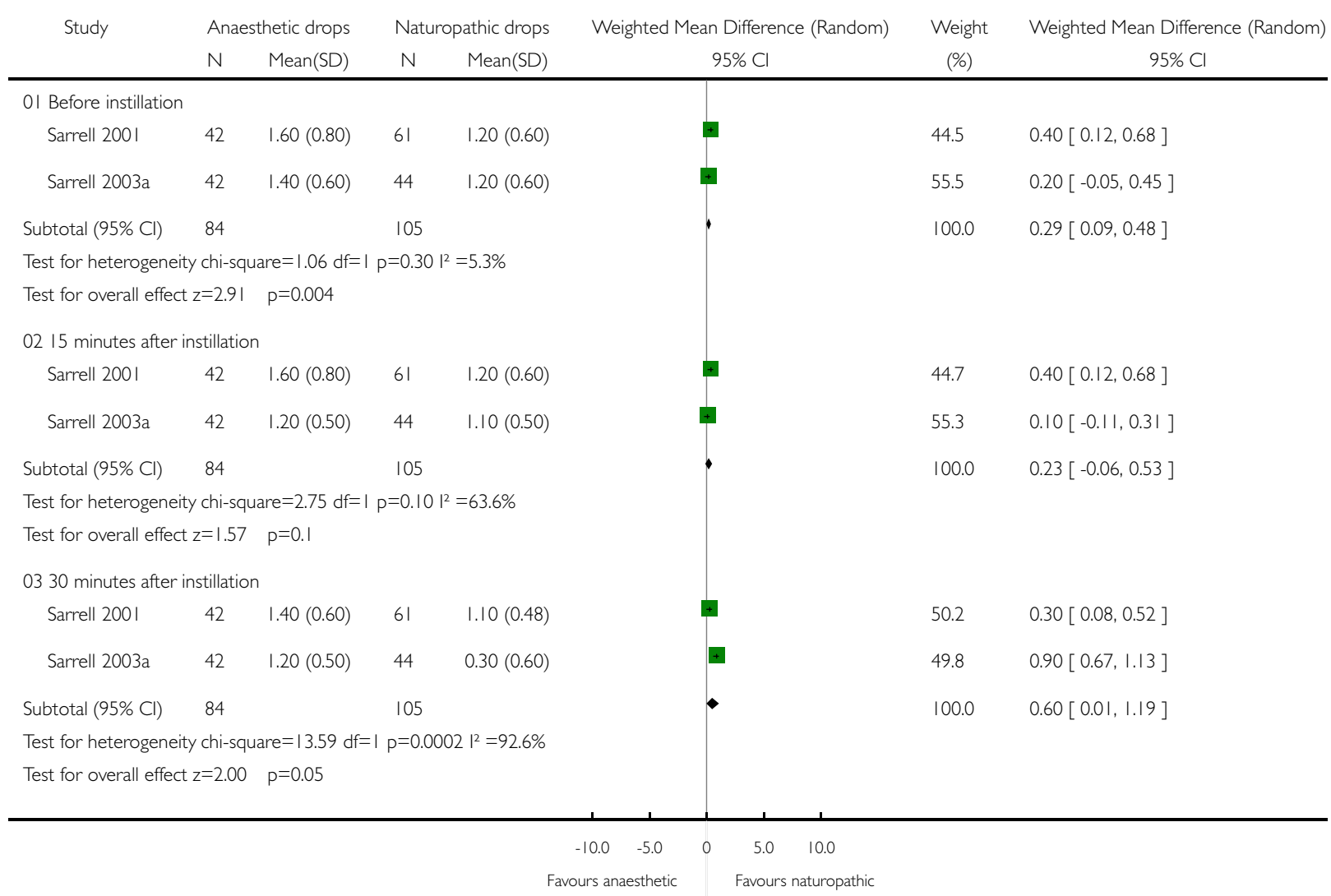

